\title{
Assessing Vegetation Function with Imaging Spectroscopy
}

\author{
J. A. Gamon ${ }^{1,2}$ - B. Somers ${ }^{3} \cdot$ Z. Malenovský ${ }^{4,5,6} \cdot$ E. M. Middleton ${ }^{6} \cdot$ U. Rascher ${ }^{7}$. \\ M. E. Schaepman ${ }^{8,9}$
}

Received: 14 January 2018 / Accepted: 16 January 2019 / Published online: 15 February 2019

(c) The Author(s) 2019

\begin{abstract}
Healthy vegetation function supports diverse biological communities and ecosystem processes, and provides crops, forest products, forage, and countless other benefits. Vegetation function can be assessed by examining dynamic processes and by evaluating plant traits, which themselves are dynamic. Using both trait-based and process-based approaches, spectroscopy can assess vegetation function at multiple scales using a variety of sensors and platforms ranging from proximal to airborne and satellite measurements. Since spectroscopic data are defined by the instruments and platforms available, along with their corresponding spatial, temporal and spectral scales, and since these scales may not always match those of the function of interest, consideration of scale is a necessary focus. For a full understanding of vegetation processes, combined (multi-scale) sampling methods using empirical and theoretical approaches are required, along with improved informatics.
\end{abstract}

Keywords Plant traits · Photosynthesis - Gross primary production (GPP) - Spectroscopy · Multi-scale sampling $\cdot$ Solar-induced fluorescence (SIF) $\cdot$ Spectral reflectance $\cdot$ Imaging spectrometry

\section{J. A. Gamon}

jgamon@gmail.com

1 Departments of Earth and Atmospheric Sciences \& Biological Sciences, University of Alberta, Edmonton, Alberta T6G 2E1, Canada

2 School of Natural Resources, University of Nebraska, Lincoln, NE 68583, USA

3 Department of Earth and Environmental Sciences, Katholieke Universiteit Leuven (KU Leuven), 3001 Leuven, Belgium

4 Surveying and Spatial Sciences Group, School of Technology Environments and Design, University of Tasmania, Private Bag 76, Hobart, TAS 7001, Australia

5 Remote Sensing Department, Global Change Research Institute CAS, Bělidla 986/4a, 60300 Brno, Czech Republic

6 Biospheric Sciences Laboratory, NASA Goddard Space Flight Center, 8800 Greenbelt Rd, Greenbelt, MD 20771, USA

7 Institute of Bio- and Geosciences, IBG-2: Plant Sciences, Forschungszentrum Jülich, Wilhelm-Johnen-Straße, 52425 Jülich, Germany

8 Remote Sensing Laboratories, Department of Geography, University of Zurich, Winterthurerstrasse 190, 8057 Zurich, Switzerland

9 University Research Priority Program on Global Change and Biodiversity, University of Zurich, Winterthurerstrasse 190, 8057 Zurich, Switzerland 


\section{Introduction}

Vegetation plays a crucial role in many Earth system processes, including carbon and water cycling, biogeochemistry, and climate regulation. Additionally, plants provide humans with a wide range of important goods and services, ranging from forest products and fodder to food production. Our society and economy depend upon the healthy function of plants as well as the resilience of ecosystems of which they are a part. Remote sensing is playing an increasingly important role in monitoring, understanding, and maintaining these critical functions.

From a remote sensing perspective, vegetation function can have several meanings. One definition refers to the detection or quantification of plant traits, structural, physiological, biochemical, or phenological attributes that represent plant functional adaptations or reveal underlying plant ecophysiological processes (Kattge et al. 2011). A complementary definition of vegetation function addresses the dynamics of essential physiological, or ecological processes themselves. This definition emphasizes variation in key processes over time and space and implies that traits themselves can be dynamic.

In this review, we consider both trait- and process-based approaches used to assess plant function, and explore the history, promise and challenge of integrating these approaches in the context of optical remote sensing. The primary focus is on optical measurements, including spectral reflectance and fluorescence sampled with spectrometers, realizing that other types of remote sensing are also useful. Since our ability to detect plant function is scale-dependent, we start with a brief discussion of scale. Next, we review plant functional traits detectable with remote sensing, followed by a consideration of proximal and airborne remote sensing. We then discuss how global satellite remote sensing has been applied to vegetation assessment along with a presentation of new directions in satellite applications. We conclude with current challenges and opportunities, and provide suggestions and directions that are likely to further advance the study of vegetation function.

\section{The Concept of Scale}

Several aspects of scale, including spatial, temporal, spectral, and biological dimensions, are relevant to any discussion of detecting vegetation function with remote sensing. The dimensions of scale are often intertwined. At finer temporal and spatial scales, underlying mechanisms or traits are best revealed, often requiring fine spectral scales. At progressively larger scales, vegetation function represents the operation of many fine-scale properties and processes that may combine in complex ways due to nonlinear responses and intricate feedbacks. Thus, to a large extent, sampling scale determines which processes are detectable and how. Consequently, any remote sensing observation of vegetation function should include a consideration of scale, with attention to underlying mechanisms at finer scales and resulting emergent properties at larger scales.

Using the example of photosynthesis, a wide range of sampling approaches can be applied according to the particular process of interest and observational scale required (Fig. 1). At the leaf level, ontogenetic and regulatory processes, and corresponding traits, are detectable using proximal spectroscopy and chamber gas exchange measurements (Gamon et al. 1997; Gamon and Surfus 1999). At the canopy level, ranging from individual crowns to more complex plant stands, airborne spectroscopy can be applied to monitor 


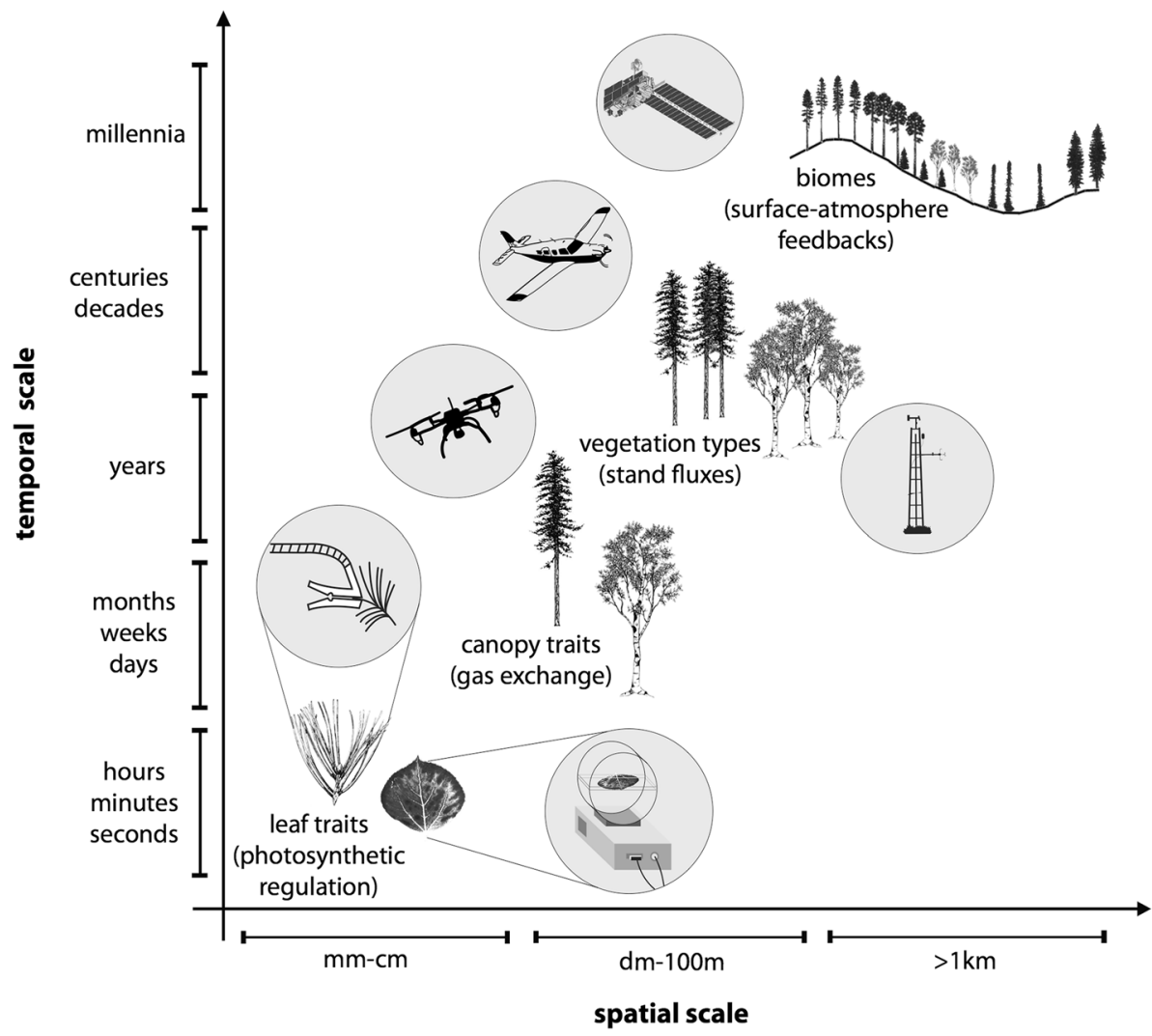

Fig. 1 Depiction of plant traits (and function) at different spatial and temporal scales. In this example of photosynthetic carbon uptake for evergreen and deciduous trees, relevant traits, corresponding functional processes, and measurement methods and terminology vary with scale (as described in the text) as well as with vegetation type (e.g., evergreen or deciduous) (Table 1). Several measurement approaches are indicated, showing spectroscopic methods in the upper left circles, and corresponding gas exchange methods in the lower right circles. Spatial and temporal scales indicated on the axes are approximate, depicting relative rather than absolute values, and refer to the processes and traits, not the measurements, which often do not match the spatial or temporal scales of the relevant processes and traits depicted, leading to scale mismatches

ecosystem photosynthesis and evapotranspiration (Fuentes et al. 2006), often measured independently using eddy covariance. At stand to biome scales, airborne or satellite remote sensing methods can detect changing vegetation productivity using optical or thermal properties, informing us of larger implications, such as altered vegetation productivity resulting from disease (Zarco-Tejada et al. 2018), plant invasion (Asner and Vitousek 2005), or widespread disturbance and climate change (Goetz et al. 2005). At stand to global scales, remote sensing can inform us of vegetation biophysical properties needed to understand emergent processes, such as the influence of surface-atmosphere mass and energy exchange on our atmosphere and climate (Bonan et al. 2002, 2003).

The topic of how to scale, or how we understand complex processes across scales, has been well discussed from a variety of perspectives (Levin 1992; Ehleringer and Field 1993; Quattrochi and Goodchild 1997; Enquist et al. 2015), providing useful insights into vegetation functional assessment. A proper study of function should consider processes 
at multiple scales, typically one level below to one level above the key process being observed (de Wit 1970, as discussed in Jarvis 1993), illustrating the importance of multiscale sampling strategies (Fig. 1). A sampling strategy should first consider the patch size or length scale (Levin 1992) of the particular process in question. Ideally, remote sensing of vegetation function involves detecting traits (functional attributes) or processes defined at a particular length scale (or patch size) and temporal scale, and matching these scales with the instrument's spatial and temporal resolution and extent. In practice, this is often difficult due to the many sensors, traits, and scales involved and due to the scale mismatch between sensors' technical capabilities and the questions of interest (Fig. 1; Table 1). Due to these technical limitations, the fundamental sampling rules acknowledging effects of scale are often violated in remote sensing. This challenge of scale, often represented as the mismatch between field sampling and remote sensing, has sometimes limited the engagement of terrestrial ecologists or biologists with remote sensing, but is being rectified as the remote sensing capabilities and scaling methodologies evolve.

An important point emerging from this discussion is that there is no single, universally applicable scale for functional studies using remote sensing. Because each remote sensing instrument and platform has a defined sampling scale, often constrained by engineering requirements and physical laws, and because the spatial and temporal resolutions of different remote sensing methods do not always match the operational scale of the vegetation process of interest, multiple platforms and sampling scales should be considered, and additional methods are often needed. These methods may involve "upscaling," the extrapolation from small to large scales through biophysical models or statistical methods (Jung et al. 2011), or "downscaling," the inversion of models or interpretation of large-scale patterns in terms of underlying fine-scale processes (Jacquemoud et al. 2009). Additionally, a nested sampling protocol (Fig. 1), rather than a single remote sensing platform or approach, can improve our understanding of function, as is often used in remote sensing field campaigns (e.g., Sellers et al. 1997). With the proper attention to scale a remote sensing campaign can reveal information regarding underlying mechanisms and emergent properties associated with a particular vegetation function. How and what we detect with remote sensing, including the "best" sampling strategy, can depend on the specific question or hypothesis to be tested, the observer's disciplinary background, the technology at hand, and the realism of the scaling model with respect to the relevant physiological and biophysical processes. Challenges in scaling imaging spectroscopy observations from leaves to vegetation canopies, including topics of natural variability and measurement uncertainty, are further described by Malenovský et al. (2019) (this issue).

\section{Vegetation Functional Traits}

Spectral reflectance offers a powerful alternative to traditional methods of understanding vegetation function because it provides a rapid, consistent, repeatable, nondestructive, and objective sampling method to assess plant traits (functional attributes) from optical properties (Gamon and Surfus 1999). These traits provide information on plant structure, water, and biochemical content (Fig. 2). Consequently, one way to assess vegetation function with remote sensing relies on the concept of plant traits, which can be described at a range of scales (Table 1). Most leaf and plant traits influence vegetation optical properties either directly or indirectly, allowing functional assessment from spectral reflectance and transmittance (Cavender-Bares et al. 2017). 


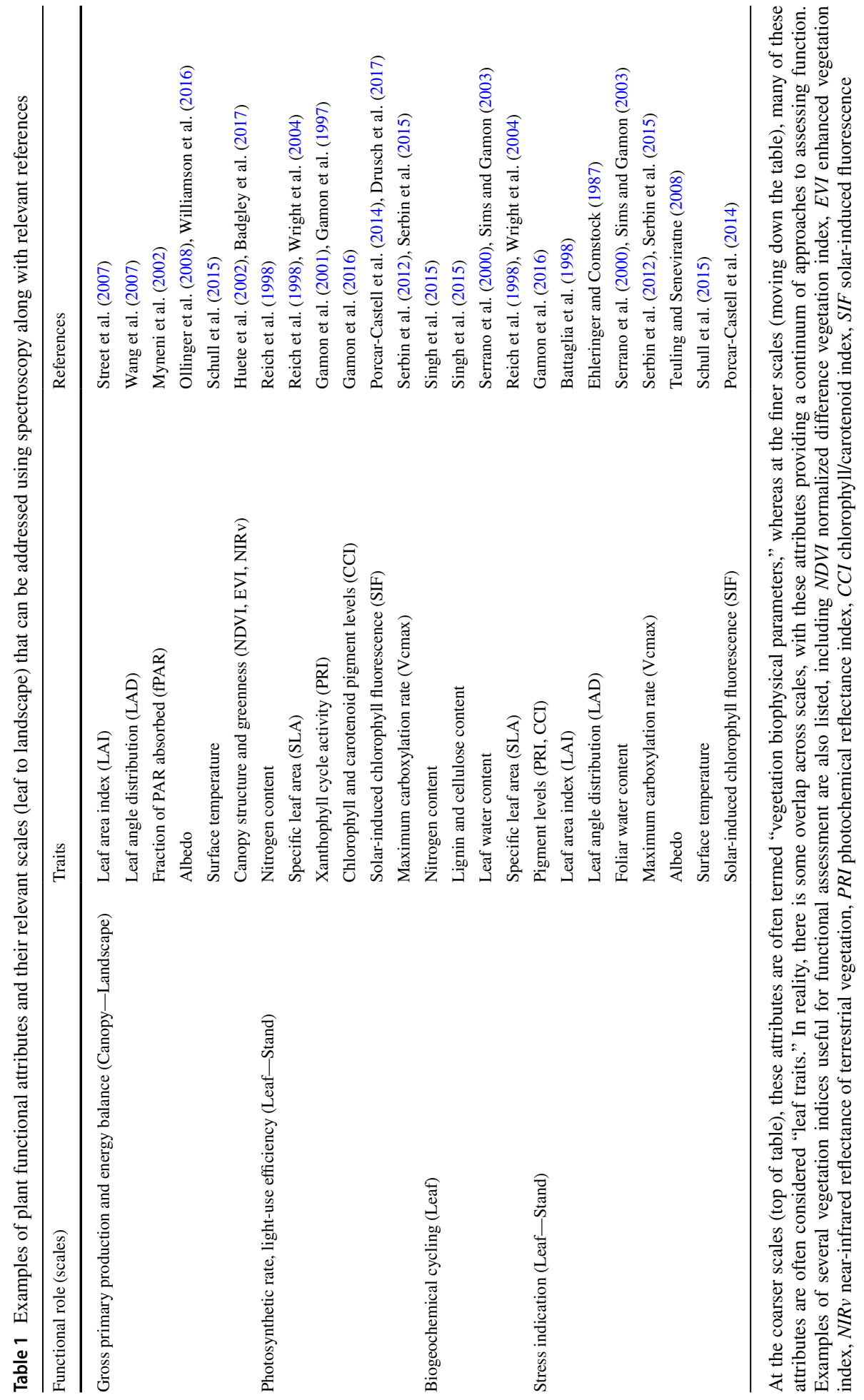




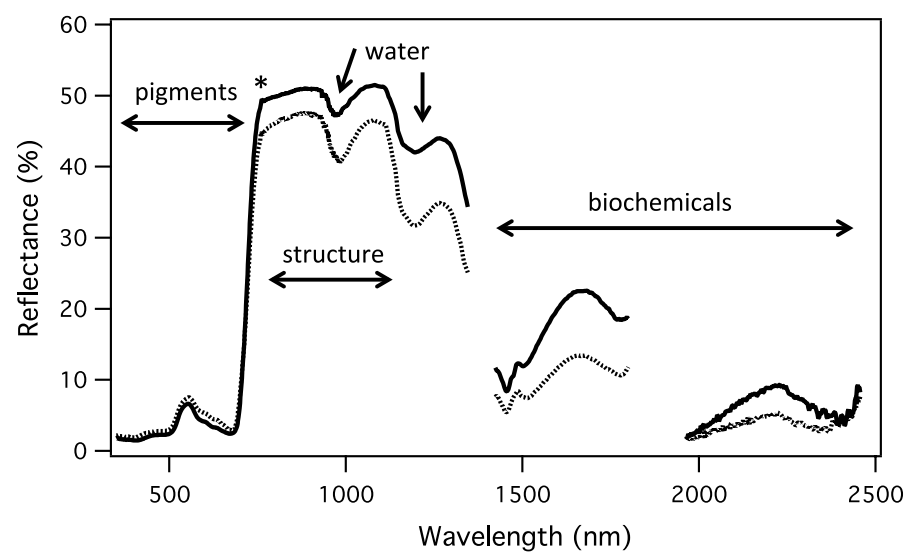

Fig. 2 Canopy reflectance spectra for deciduous poplar (Populus balsamifera, solid line) and evergreen spruce (Picea glauca, dotted line) canopies, showing spectral regions with information on pigment content, water content, biochemical content, and leaf or canopy structure. Alternatively, full-spectral information can be used to derive these and other leaf traits, as discussed in the text. Asterisk (*) indicates the location of the $\mathrm{O}_{2}$-A band (fluorescence signal). Data gaps occur in wavelengths of strong atmospheric water absorption. Tree seedlings, sampled June 22, 2016, with a field spectrometer (PSR-3500, Spectral Evolution, Lawrence, MA, USA), in Edmonton, Alberta, Canada

There is a rich literature on plant traits at the leaf scale, much of which is now being related to leaf optical properties via reflectance spectra (e.g., Serbin et al. 2014). Leaf traits are often defined in terms of foliar constituents (e.g., biochemical or water content), or in terms of leaf structure (e.g., surface area, thickness, specific leaf area, or mass per area) (Cornelissen et al. 2003; Kattge et al. 2011; Homolová et al. 2013). Alternatively, leaf traits can be described in more direct functional and dynamic terms, including carboxylation potential, Vcmax (Serbin et al. 2012), photosynthetic rates, or radiation-use efficiency (Gamon et al. 1997). Remotely sensed data do not always map directly onto plant functional traits. Instead, leaf and plant traits can be considered latent variables best represented by transformations or linear combinations of multiple spectral features (Feilhauer et al. 2017). While not all traits are equally retrievable by remote sensing, many hidden traits can be correlated with more accessible traits, facilitating their characterization even when they cannot be directly detected with spectroscopic methods. In these cases, the functional connections between reflectance spectra and functional properties may not yet be entirely clear. Part of the power of spectra for assessing traits is that they provide information from many wavelengths, sometimes into a single metric as represented by a spectral index, or using many wavelengths simultaneously as depicted in a coefficient spectrum (Serbin et al. 2014).

In addition to leaf traits, functionally important vegetation properties can also be defined at larger scales (e.g., canopy traits, vegetation types, and biomes), and these categories can often be viewed as aggregations of underlying leaf or plant traits (van Bodegom et al. 2014). For example, deciduous and evergreen vegetation types tend to have distinct associations of leaf traits that are spectrally discernable (Gamon et al. 1997) (Figs. 1, 2). A clear understanding of canopy and stand structure is needed to understand the "scaleability" of leaf traits, which may depend on the particular trait and context, and can vary with vegetation type. For example, under the right conditions of uniform, closed vegetation stands, xanthophyll cycle pigment activity (an indicator 
of photosynthetic light-use efficiency) can be directly detected at larger scales (Gamon and Qiu 1999; Stylinski et al. 2002), offering the possibility of stand-scale assessment of photosynthesis using aircraft or satellite remote sensing. However, complex and dynamic canopy structure can readily confound detection of this leaf photoprotective signal (Barton and North 2001; Gitelson et al. 2017). Consequently, accounting for changing Sun angle, view angle, and canopy structure can often improve the interpretation of the underlying physiological signals (Drolet et al. 2008; Hilker et al. 2008; Middleton et al. 2009, 2016; Hilker et al. 2011).

Due to the complexity of canopy structure, some important leaf traits (e.g., nitrogen content) may not always be directly detectable at stand scales (Knyazikhin et al. 2013). However, because foliar nitrogen levels indirectly influence canopy structure, nitrogen levels can often be inferred, even when not directly measured, with remote sensing (Ollinger et al. 2008; Ollinger 2011; Townsend et al. 2013). These examples of leaf traits correlating with higher level traits demonstrate that a proper understanding of the particular context can facilitate the assessment of plant function from remote sensing, even when the underlying leaf traits are not directly detectable at larger scales. Consequently, even at larger scales sampled by aircraft and satellite, the concept of leaf traits can have utility, and can often be expressed in suites of characteristics that collectively define "plant strategies" (Grime 2006) or "optical types" (Ustin and Gamon 2010), both variations on the plant functional type concept. Vegetation functional types are commonly used in many global models of ecosystem function and Earth system science as a way to classify complex vegetation biophysical properties into a few simplified "types," facilitating model simulations (Bonan et al. 2002, 2003; Pavlick et al. 2013; van Bodegom et al. 2014). The concept of vegetation optical types, sometimes called spectral types or spectral species (Feret and Asner 2014), represents an attempt to define functionally significant optical properties (or spectral patterns) related to plant traits. In this way, defining vegetation functional types in terms of optical types (spectral types) can simplify studies of large-scale vegetation processes.

Advances in spectroscopy and statistical techniques have led to reliable methods to assess leaf traits, sometimes rivalling traditional metrics involving structural or wet chemical measurements. Traits can be derived from specific spectral regions using vegetation indices (Table 1; Fig. 2) (e.g. Malenovský et al. 2013). Alternatively, traits can be retrieved from optical measurements using statistical approaches such as partial least squares regression (PLSR, Roelofsen et al. 2014; Serbin et al. 2014). However, these methods have not yet revealed universal relationships. Part of the reason lies in the evolutionary convergence of plant traits; many plant species have evolved similar solutions to the same environmental challenges, and it is often the subtle variation in these features over time or across environmental gradients that can be most informative. Most published studies linking optical properties and plant traits are limited to a single point in time, generally near the center of the growing season (Homolová et al. 2013). Thus, they fail to capture the full variation in conditions or plant traits expressed in the life of an individual organism, canopy, stand, or ecosystem. Not surprisingly, results from one season do not always apply well to datasets collected in another season (Chavana-Bryant et al. 2017). Until we obtain extensive, and uniform, time series of optical data, the full evaluation of plant traits through optical properties will remain a work in progress. Fully understanding the links between spectral space and trait space represents an ongoing challenge, in part due to the large data volume, involving many traits and spectral features along with other independent variables (e.g., time, space, and observation geometry). While progress is being made on the definition and application of optical types (Gamon et al. 1997; Ustin and Gamon 2010; Feret and Asner 2014), we currently lack a comprehensive theory of optical types, or a full understanding 
of how they relate to plant traits. Opportunities lie in the full exploration of the effects of temporal and spatial scales, a topic more fully explored below (see Sect. 7).

Plant traits can also be related to spectra through forward physical modeling (Schneider et al. 2014) and inversion of leaf or coupled leaf-canopy radiative transfer models at the leaf level (e.g., PROSPECT, Jacquemoud and Baret 1990; Malenovský et al. 2006), or the canopy level using one-dimensional models (e.g., SAIL, Verhoef 1984; or SCOPE, van der Tol et al. 2009) or three-dimensional models (e.g., DART, Gastellu-Etchegorry et al. 2017). For more detailed discussion of such models, see Verrelst et al. (2019) and Malenovský et al. (2019) (both in this volume).

\section{Proximal Spectrometry}

Many of the current advances in spectral reflectance for vegetation function are derived from proximal spectrometers. These include handheld portable spectrometers and groundbased imaging spectrometers (Pinto et al. 2016, 2017), as well as instruments mounted on towers (Hilker et al. 2011), mobile platforms (Gamon et al. 2006; Sims et al. 2006), and unmanned aerial vehicles (UAVs, also known as drones; Burkart et al. 2014; Lucieer et al. 2014; Malenovský et al. 2017). Many of these studies have been coordinated with flux tower observations, facilitating calibrations with independent data and cross-site comparisons (see reviews by Gamon et al. 2010; Balzarolo et al. 2011; Gamon 2015).

A key advantage of proximal sampling has been its ability to provide rich time series of data, which have been difficult to obtain using airborne or satellite platforms. These instruments sample at scales that can be readily related to leaf traits and where process measurements (e.g., carbon or water vapor fluxes, changing pigment content, or dynamic chlorophyll fluorescence) can be independently validated using experimental approaches and coupled measurements at similar scales. They are also particularly well suited to exploring the functional regulatory, ontogenetic and physiological mechanisms that underlie changes in optical properties at larger scales. Hence, proximal instruments provide useful experimental tools to explore new ways to sample vegetation function and to validate optical measurements at larger scales. A disadvantage is their restricted spatial coverage, limited distribution across biomes and vegetation types, and lack of standardization in sensors and protocols, making it difficult to draw general conclusions from individual field studies (Gamon et al. 2010; Gamon 2015). The large number of these studies, combined with improved informatics and statistical or other modeling tools for upscaling, promise to advance our understanding of vegetation function, particularly when combined with aircraft or satellite observations. Proximal sensing can also lead to innovation in sensor technologies and applications that can inform the design and interpretation of future airborne or spaceborne sensors.

\section{Airborne Remote Sensing}

Increasingly, airborne imaging spectrometers are being applied to assess vegetation traits and functional processes. These instruments typically collect measurements in either the "full-range" VSWIR (visible-short-wave infrared) wavelengths or in the more limited VNIR (visible-near-infrared) range. Full-range sensors offer a wider range of options for detecting plant traits, but are more expensive, heavier, and more difficult to maintain and operate. VNIR 
sensors, while more limited in spectral coverage, are much lighter and less expensive, providing an easier entry point into the world of airborne imaging spectrometry. Depending upon their intended purpose, these instruments range in spectral resolution from $10 \mathrm{~nm}$ for typical reflectance applications to $\leq 0.3 \mathrm{~nm}$ in the case of airborne spectrometers intended for detection of solar-induced fluorescence (SIF, Rascher et al. 2015; Schaepman et al. 2015; Wieneke et al. 2016). Pixel sizes (IFOV) can approximate $1 \mathrm{~m}^{2}$, a scale fine enough to resolve individual plant canopies in the case of large trees. This combination of fine spatial and spectral resolution is particularly useful for evaluating spatial patterns in plant traits (Asner and Martin 2016).

From the perspective of vegetation dynamics, a primary limitation of airborne platforms has been the difficulty and expense of obtaining regular observations to yield sufficiently large and frequent time series of vegetation function. Typical airborne datasets contain single overpasses, or at best a handful of measurements over a short time span (e.g., several within-day, or "diurnal" acquisitions), which are obtained a few times in a single growing season. Such limited temporal frequency restricts the power for assessing functional processes occurring at different time scales. On the other hand, even single aircraft overpasses can provide useful assessments of spatial patterns in functional traits (Homolová et al. 2014; Asner and Martin 2016) illustrating the benefits of inferring function from trait-based approaches.

Airborne field campaigns with various generations of the Airborne Visible/InfraRed imaging Spectrometer (AVIRIS) sensor, such as the AVIRIS Classic and the AVIRIS-NG, have provided good examples of the power of imaging spectrometry to detect vegetation function. Many of these campaigns have assessed plant function through photosynthesis, water status (Fuentes et al. 2006; Serbin et al. 2015; Somers et al. 2015; Asner et al. 2016a), or nutrient status (Asner and Vitousek 2005). The HyPlant airborne sensor (Rascher et al. 2015), developed in preparation for the forthcoming FLEX satellite mission (Kraft et al. 2013; Drusch et al. 2017), with an expected launch in late 2022, provides very high spectral resolution radiance or reflectance suitable to detect chlorophyll fluorescence and foliar pigment content, both powerful indicators of photosynthetic activity (Rossini et al. 2015; Simmer et al. 2015; Wieneke et al. 2016; Middleton et al. 2017). The Airborne Prism Experiment (APEX), serving as an airborne precursor for a space-based imaging spectrometer mission, demonstrates simultaneous high-resolution spectroscopic retrievals for the atmosphere, the non-vegetated surface, and chlorophyll fluorescence (Schaepman et al. 2015). Numerous airborne campaigns focusing on plant traits have provided promising tests of trait-based approaches to assess vegetation function (Asner et al. 2016b; Schneider et al. 2017). Despite limited revisit time, airborne spectrometry remains a powerful tool for demonstrating the ability of full-spectral information to improve our understanding of vegetation function. Emerging monitoring networks, such as the NEON program (funded by the US National Science Foundation), are beginning to provide airborne imaging spectrometry capability along with proximal spectral measurements across a network of sites in the continental US, offering new opportunities for the systematic exploration of vegetation function across scales for representative ecosystems (Kampe et al. 2010).

\section{Satellite Remote Sensing}

\subsection{Brief History of Optical Satellites for Vegetation Monitoring}

Historically, spatially and temporally extensive series of spectral imagery from space useful for assessing vegetation function have been limited to a few of the over 1000 global 
orbiting satellites. Most of these have had limited spectral coverage, constraining their utility for vegetation functional studies. Many of the multi-spectral orbiting sensors have been radiometers with a small number (e.g., 2-8) of relatively wide (e.g., $\geq 20-30 \mathrm{~nm}$ ) spectral bands related to a handful of biophysical traits, some related to green vegetation structure (e.g., LAI and fPAR, Table 1). Long-term repetitive observations have been obtained by the USGS Landsat Thematic Mapper/Enhanced Thematic Mapper (TM/ETM) series, and the NOAA Advanced Very High Resolution Radiometer (AVHRR) series. Despite the fact that the NOAA missions, built primarily for weather observations, were not designed or optimized for vegetation monitoring, they fortuitously have provided important insights into vegetation function over large regions. The discovery that a combination of red and near-infrared wavelengths used together could track seasonality of green vegetation biomass and leaf area index (Rouse et al. 1974; Tucker 1979), has been applied to the interpretation of AVHRR imagery at continental and global scales, providing a revolutionary view of vegetation functional dynamics at continental scales (Tucker et al. 1985), and allowing globally consistent vegetation classifications incorporating seasonal dynamics (DeFries and Townshend 1994).

The MODIS (Moderate Resolution Imaging Spectroradiometer) carried on the Terra (launched in 1999) and Aqua (launched in 2002) satellites have emerged as important sensors for global biospheric monitoring. At its conception in the 1990s, the MODIS data system EOSDIS (the Earth Observing System Data and Information System) was the "largest and most complex data system every constructed" (Marshall 1993). Key to MODIS's success has been the availability of standardized data products, enabling the establishment of a critical terrestrial database spanning many years that has led to scientific advancements in many earth science disciplines. The operational collection and processing of 36 spectral bands across the full shortwave and infrared regions from the Terra and Aqua MODIS have yielded invaluable time series of atmospheric, marine, and terrestrial products. These 36 bands include 20 reflective shortwave and 16 emitted infrared bands. Seven of the reflective bands are used for terrestrial and atmospheric monitoring land discrimination, covering the VSWIR spectral regions, with varying bandwidths (20-50 nm, Fig. 3). Some of these are used to provide a few key land products, including LAI and FPAR that are widely used in studies of vegetation dynamics (Table 1). Additionally, nine narrower $(10 \mathrm{~nm})$ "ocean color" bands in the visible spectrum (blue bands, Fig. 3) are also part of the MODIS suite at coarser spatial scales $(\sim 1 \mathrm{~km}$ for nadir views). These ocean bands were not originally intended for vegetation applications, and in earlier MODIS Collections (1-5), they were processed separately from land bands. Consequently, until recently, researchers using the "ocean" bands for terrestrial vegetation studies have had to conduct their own processing and atmospheric corrections, a situation rectified with Collection 6.

Global vegetation products developed from MODIS, including the NDVI, the Enhanced Vegetation Index (EVI; Huete et al. 2002) and related products such as leaf area index (LAI) and the fraction of absorbed photosynthetically active radiation (fPAR, or fAPAR; Myneni et al. 2002), are used to derive gross and net primary production (GPP and NPP) (Table 1). These spectrally based products have been used extensively for assessing regional and global vegetation functional dynamics, including photosynthetic activity and stress or disturbance responses. A key example is the MODIS MOD17 NPP product, based on the light-use efficiency (LUE) model, which provides the first consistent, multi-year depictions of global terrestrial NPP (Running et al. 2004), describing both seasonal phenology and interannual variation in vegetation photosynthetic activity at continental scales, allowing attribution of NPP anomalies to the El Niño-Southern Oscillation (ENSO), drought and other climate factors (Zhao and Running 2010). 


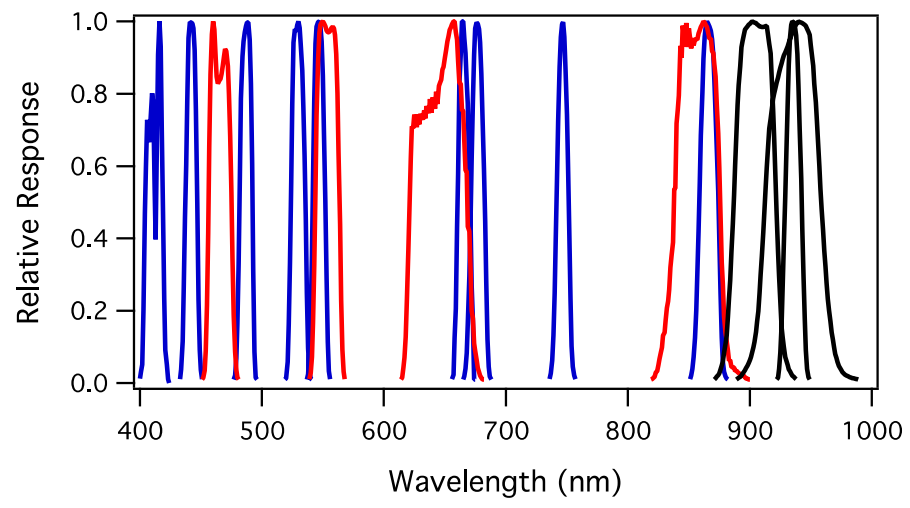

Fig. 3 Normalized spectral response functions of the MODIS sensors showing ocean bands (blue), land bands (red), and atmospheric bands (black)

New MODIS products for vegetation function continue to emerge. Although MODIS ocean bands were not originally intended for vegetation, the recent MAIAC reprocessing (Lyapustin et al. 2011a, b), as part of MODIS Collection 6, now provides surface reflectance products from both land and ocean bands over terrestrial regions from each MODIS sensor at daily time steps at the equator and multiple times a day in high latitudes due to orbital overlap near the poles. Several studies have demonstrated that combining land and ocean bands over terrestrial regions offers improved assessments of plant traits linked to photosynthetic activity (Rahman et al. 2004; Drolet et al. 2008; Garbulsky et al. 2008; Goerner et al. 2009; Gamon et al. 2016; Middleton et al. 2016). While this new band combination still lacks the spectral detail needed to assess many specific plant traits, it contains sufficient information to detect relative chlorophyll and carotenoid pigment levels, important indicators of plant stress and photosynthetic activity. This new information on plant pigment ratios improves our assessment of photosynthetic phenology, particularly for evergreen vegetation, which has been difficult to assess using greenness indices like NDVI (Gamon et al. 2016). Similarly, a new MODIS product, fAPARchl (the fAPAR fraction attributable to chlorophyll only), has been developed (Zhang et al. 2009, 2013, 2016) and has been proposed as a standard product. These findings are consistent with a history of studies showing that retrievals of plant pigments from remote sensing provide useful information about vegetation photosynthesis, productivity, stress, and overall health (Gitelson et al. 2005; Ustin et al. 2009). In global, cross-biome comparisons, NIRv, a new combination of red and NIR band reflectance from MODIS, yields improved GPP estimates relative to the NDVI (Badgley et al. 2017). These newly emerging indices are a testament to the value of consistent satellite time series and a persistent, accessible data system for advancing our understanding of vegetation function.

Since the historical satellite records contain imagery collected with only a few wide spectral bands, they cannot distinguish many important vegetation functional traits and processes detectable only with narrow-band $(\leq 10 \mathrm{~nm})$ spectral features. Furthermore, many of the satellite products are temporally aggregated; largely to address problems with varying cloud cover and sensor view angles, past MODIS EVI and NDVI products have been primarily available as composite values at 16-day (and recently at 8-day) time steps, which limits their ability to detect temporal dynamics, particularly during periods of rapid change (e.g., spring green-up or unexpected disturbance events) (Gamon et al. 2013). 
Newer MODIS collections (e.g., Collection 6) offer daily time series of MODIS reflectance products, enabling a finer look at vegetation dynamics that offers to better resolve these events. Another limitation of the historical satellite time series has been the requirement to integrate other data (e.g., meteorological data) collected from different instruments on different temporal and spatial scales to facilitate quantitative interpretation of the spectral information (Running et al. 2004; Heinsch et al. 2006). Consequently, while current multiband satellite products reveal broad patterns of a few key emergent properties of terrestrial ecosystems and biomes at the regional to global scales, they are not able to resolve detailed processes at the scale of individual land management units, or at specific experimental sites within observational networks (e.g., the flux tower network). Consequently, many underlying mechanisms remain partly obscured, leaving gaps in our understanding of vegetation function.

Despite their limitations, these global satellite products have demonstrated the power of consistent global surface reflectance products for assessment of terrestrial photosynthetic dynamics. While many underlying mechanisms remain hidden due to their coarse sampling scales, the consistent time series over many decades has provided an invaluable perspective on vegetation change and essential vegetation fields for global Earth system models (Garonna et al. 2016). These models include Dynamic Global Vegetation Models (DGVMs, e.g., Bonan et al. 2003; Pavlick et al. 2013; van Bodegom et al. 2014), soil-vegetation-atmosphere-transfer (SVAT) models depicting surface-atmosphere interactions (Arora 2002), nested physiological-climate models (Sellers et al. 1996a, b), and global models of net primary production (NPP, Running et al. 2004). This power to reveal vegetation function is continually being expanded with new reanalyses, and by adding additional satellite data.

Since 2015, a follow-on satellite to continue the MODIS record is the Joint Polar Satellite System, with a Visible Infrared Imaging Radiometer Suite (VIIRS). Unfortunately, this satellite has fewer bands than MODIS, limiting its utility for vegetation functional assessment. Today, the Copernicus Sentinel program of the European Space Agency (ESA) for the European Commission (EC) is setting new standards for operational multi-spectral Earth Observation with Sentinel-2 and Sentinel-3 (Aschbacher and Milagro-Pérez 2012; Malenovský et al. 2012). The two synchronously flying satellites Sentinel-2A and Sentinel-2B provide 12 optical bands with a spatial resolution of 10-30 meters and a global revisiting time of less than 5 days (Drusch et al. 2012). Besides these operational flagships of ESA, the recently launched (August 2017) VEN $\mu$ S mini-satellite (Israel Space Agency and CNES, France) offers 12 spectral bands (16-40 nm wide) and a unique orbit revisit scheme.

\subsection{Hyperspectral Satellites}

In recent years, several satellite missions demonstrating the capability of imaging spectrometers, also known as hyperspectral scanners, have been placed in orbit. These missions have provided limited geographical coverage, with imagery collected on user request, and include the NASA EO-1/Hyperion and the ESA CHRIS Proba. The Hyperion sensor provided limited image data collection at 30-m spatial resolution upon user request over a 17-year lifespan (2000-2017). All of these datasets are now freely available through the USGS archive. Recent analyses from the Hyperion collection demonstrate the power of imaging spectrometry for evaluating spatial patterns of net ecosystem $\mathrm{CO}_{2}$ exchange (Campbell et al. 2013) and also vegetation functional types based on spectral patterns 
(Somers and Asner 2012; Huemmrich et al. 2013). The Compact High Resolution Imaging Spectrometer (CHRIS) sensor has a multi-angular viewing capability (2 forward, a nadir and 2 backward viewing angles) for a better understanding of the bidirectional reflectance distribution function (BRDF) of terrestrial surfaces. It collects up to 150 channels (spectral range of 400-1050 $\mathrm{nm}$ ) with a ground sampling resolution of 17 or $34 \mathrm{~m}$ over preselected sites on demand since 2001. A VIS-NIR spectrometer, the Hyperspectral Imager for the Coastal Ocean (HICO), was flown (2009-2014) on the International Space Station (ISS), and its utility for ecosystem function was demonstrated by Huemmrich et al. (2017).

The hyperspectral or spectroscopic observations acquired from space thus far have provided a strong foundation for the further development of satellite imaging spectrometers with global coverage. Hyperspectral missions of note include the Medium Resolution Imaging Spectrometer (MERIS), which had 15 programmable bands (FWHM 2.5-30 nm) and flew from 2002 to 2012, and the CHRIS-Proba which has 200 narrow bands that can be combined into wider (e.g., 18) bands at varying spatial coverage $\leq 30 \mathrm{~m}$. The two European Sentinel-3 satellites continue the mission concept of MERIS with an increasing number of optical bands (21 vs. 15 bands) and an improved optical performance (Donlon et al. 2012). The DLR Earth Sensing Imaging Spectrometer (DESIS; Eckardt et al. 2015) sponsored by the German Space Agency, was deployed on the International Space Station in June 2018. Additional proposed spaceborne imaging spectrometers promise to further expand our understanding of vegetation function using detectors with much higher spectral, spatial and temporal resolution. Presently, there are several new missions in various stages of planning or deployment. The space agencies of Italy and Israel are preparing the PRISMA mission (Amato et al. 2013) for launch in 2018-2019. The EnMAP mission (Germany) (Guanter et al. 2015a) and NASA's HyspIRI (Hyperspectral Infrared Imager) mission, (Lee et al. 2015), recently evolved into the Surface Biology and Geology (SBG) mission, will follow in the next few years. These emerging satellite instruments offer much richer spectral information than the history of multi-band Earth observation satellites mentioned above, and promise to expand the opportunities for assessing specific plant functional traits and dynamics.

\subsection{Solar-Induced Fluorescence (SIF)}

Recent examples of fortuitous applications of satellite data to assess vegetation function have arisen from several very high spectral resolution but coarse spatial resolution global satellite sensors designed for atmospheric gas sampling, including the Greenhouse gases Observing SATellite (GOSAT), the Global Ozone Monitoring Experiment-2 (GOME-2), and NASA's Orbiting Carbon Observatory (OCO-2). These instruments have extremely high spectral resolution $(<0.5 \mathrm{~nm})$ with the capability of resolving solar Fraunhofer lines and atmospheric (telluric) absorption features that enable detection and quantification of a tiny solar-induced chlorophyll fluorescence (SIF) signal emitted from vegetation. This SIF signal increases with the amount of radiation absorbed by chlorophyll (APAR), and decreases with the amount of absorbed radiation that is dissipated as heat within leaves under stress (Porcar-Castell et al. 2014), providing a direct link to photosynthetic activity (gross primary productivity). These "ultra-spectral" sensors used for SIF detection offer new possibilities for global assessment of terrestrial photosynthesis or gross primary production (GPP), albeit at very coarse temporal and spatial scales (Frankenberg et al. 2011; Joiner et al. 2011; Guanter et al. 2012). A primary drawback of these global satellites has been that retrieval of the weak fluorescence signals requires averaging over large time steps 
and regions of the planet, obscuring fine-scale dynamics needed to explain underlying mechanism. This limitation is spurring development of new sensors and applications of spectrometry and fluorometry from airborne (Rascher et al. 2015; Schaepman et al. 2015) and proximal platforms (Burkart et al. 2014, 2015; Wyber et al. 2017). These ongoing advances combining airborne and proximal remote sensing offer to further clarify the functional links between passive fluorescence (SIF) and seasonally dynamic pigments levels (Gamon et al. 2016; Springer et al. 2017). Our growing understanding of photosynthetic dynamics will be further improved with the enhanced capabilities of the newly launched TROPOMI sensor (Guanter et al. 2015b), and the planned European Space Agency's FLEX (Fluoresence Explorer) satellite mission, designed specifically to directly address pigments and SIF simultaneously at global scales (Kraft et al. 2013; Drusch et al. 2017).

\section{Current Challenges and Opportunities}

A primary challenge in the remote sensing of vegetation function lies in extracting reliable, quantitative metrics of functional properties and processes that can be universally applied. Part of this challenge derives from the fact that remote sensing methods typically operate at spatial and temporal scales different from the functional processes or traits of interest (Fig. 1). Remarkably, despite this scale mismatch, plant traits and processes can often still be detected, even if the underlying mechanisms of signal transmission and detection remain partly unclear (Townsend et al. 2013; Schweiger et al. 2017). Developing a better understanding of the reasons for this convergence across scales, and understanding why it succeeds in some cases and fails in other cases, remain fundamental tasks. Potential solutions can be found in applying the full range of instrumentation from proximal sensors to global satellites to address scaling methods. Additional solutions lie in integrating physical, biological, and statistical approaches, and further exploring the concept of "optical types," representations of plant traits through patterns in spectral reflectance (Ustin and Gamon 2010), also called "spectral types" or "spectral species" (Feret and Asner 2014). Due to the multiple dimensions and high volume of data involved, greater attention to informatics will be needed. These challenges and opportunities are discussed in more detail below.

\subsection{Integrating Trait-Based and Process-Based Approaches}

The divergent methods to assess vegetation function based on static traits versus dynamic processes often seem to be distinct conceptual and practical approaches. However, these perspectives can be combined for greater insight, and a current opportunity lies in integrating trait- and process-based approaches. Traits, while sometimes applied categorically, can be depicted along a continuum (Wright et al. 2004). This continuum also has a time dimension (Chavana-Bryant et al. 2017). Capturing the full temporal dynamics of plant traits, while rarely attempted, can provide better insights into vegetation processes. The lack of consistent time series of optical properties, except for some proximal ground- or towerbased datasets, limits our current understanding of plant function using remote sensing. The advent of global imaging spectrometers with regular repeat cycles will greatly expand our understanding of vegetation processes at multiple scales, particularly when combined with proximal and airborne spectrometers. Similarly, spectral patterns can reveal information on both states and processes, allowing community properties like spectral diversity to be related to ecosystem processes like productivity (Wang et al. 2016a, b). In this way, 
integrating traits and processes can help quantify functional diversity (Schneider et al. 2017, Schweiger et al. 2017, 2018) and inform our understanding of ecosystem services (Braun et al. 2017).

\subsection{Bridging Spatial and Temporal Scales}

To what extent leaf traits can be detected at canopy or larger landscape scales observed by global spaceborne missions remains an open question, with good evidence both for and against upscaling of functional traits. The current literature on this topic is not entirely clear, with some authors questioning the detectability of certain leaf traits using optical remote sensing (Knyazikhin et al. 2013) and others noting that they could be detected under the right conditions (Townsend et al. 2013). Not all optical traits scale equally; multiple light scattering and absorption of plant canopies can confound some features, but accentuate other features allowing some leaf traits but not others to be easily detectable at canopy and stand scales. A number of studies report detection of plant functional traits with airborne imaging spectrometry (Asner et al. 2016a, b; Schneider et al. 2017), but the question remains: What exactly is detected as we move to progressively larger scales? A more complete answer to this question requires a clear methodology with well-defined hypotheses and conceptual frameworks, as well as physical models simulating imaging spectroscopy signals.

Scaling limitations are being transcended with new computational methods and sampling approaches. Since remote sensing technology (including observational instruments, computational power, and physical and statistical models) is rapidly changing, the topic of how to assess function across scales needs to be periodically revisited and updated. New statistical methods, including advanced machine learning approaches, are emerging that are greatly facilitating data analysis across scales (Verrelst et al. 2016). Improved comprehensive mathematical approaches to scaling (e.g., physically based radiative transfer models) are also relevant, as described in Verrelst et al. (2019) and Malenovský el al. (2019) (this issue).

While these models capture static vegetation biophysical and structural properties well, most do not adequately describe transient dynamics in plant functional properties mediated by physiological processes, such as chloroplast movement, leaf movement or rapid biochemical and changes associated with light regulation. Although some models are capable of resolving complex photon-vegetation interactions in three-dimensional (3D) space (Gastellu-Etchegorry et al. 2017), they cannot provide the same flexibility and realism that can be obtained from dynamic empirical measurements. Development of new hybrid models is a move in the right direction, where radiative transfer with simulations of dynamic energy budgets at the canopy/landscape scale is combined with photosynthetic biochemical models describing functional leaf optical properties tied to physiological regulation at the leaf scale (e.g., SCOPE, Timmermans et al. 2013). This direction should be considered in models accounting for 3D spatial heterogeneity, which can help us to better understand the impact that less dynamic structural features have on the ability to detect rapidly changing biochemical physiological processes. The development of GUI-driven models, such as the Automated Radiative Transfer Models Operator (ARTMO, http://ipl.uv.es/artmo/) offering wider accessibility in a user-friendly format, represents a recent advance that offers to facilitate the application of models to questions of vegetation function. In all cases, outputs 
of model simulations need to be tested against empirical measurements for a wide range of vegetation types to help clarify underlying mechanisms.

Clearly, the topic of scaling functional traits needs further study. Because spectra are temporally dynamic, often displaying considerable redundancy (leading to collinear responses), and because plants exhibit functional convergence (Ollinger 2011), it is easy to get the right answer for the wrong reason (or vice versa), i.e., because of non-causal relationships. Without attention to scale, traditional mapping approaches, while they may imply functional differences, may not be sufficient to fully detect functional processes, in part due to complexities of spatial scale, but also due to the temporal dynamics of plant traits (Chavana-Bryant et al. 2017). Unless temporal dynamics are fully considered, there will remain some question as to the accuracy of plant functional characterization.

\subsection{Conceptual Advances in Integrating Physical and Biological Approaches}

An understanding of the scaling questions would benefit from an integration of ecological theory with physical principles of radiative transfer (Kattenborn et al. 2017), but this has yet to be fully accomplished. While a complete radiative transfer modeling capability will have to consider complex physical and physiological processes (e.g., turbulent air transfer and the rapid physiological responses to dynamic light regimes), it can also be better guided by ecological theory that can help explain how canopies, stands, and landscapes are constructed from underlying rules guiding plant evolution and adaptation.

Ecological theory states that form follows function. This principle, which has sometimes been labeled "functional convergence" (Field 1991; Ollinger 2011), allows us to detect functional patterns and differences with imaging spectrometry. An elaboration of this concept states that plant biochemistry and structure have evolved to meet the functional goal of efficient resource capture and organism protection (among other goals), and that detectable differences in these traits with remote sensing reflect different adaptations or evolutionary responses, or "strategies" (Grime 2006). Fundamentally, this is an economic argument, stating that plants tend to follow economic rules when displaying functional properties (Bloom et al. 1985). The scaling of plant traits can be guided by principles of functional convergence, which can involve coordination of plant traits that simplify the challenge of addressing plant function from remote sensing. Different functional solutions can be addressed by a clearer definition of optical types representing optically detectable suites of functionally important plant traits. A better integration of theory with models and empirical measurements will be needed to accomplish these goals.

\subsection{Informatics Needs for Databases, Archives, Tools, and Protocols}

Spectral assessment of vegetation function presents new challenges for informatics in the collection, storage, processing, and archiving of increasingly large data volumes. This challenge exists both for the trait-based approach, where large numbers of plant traits are being assessed with reflectance spectra, and for the process-based approaches, where the additional demands of time-series analyses arise. Currently, unlike the development of databases and related tools that are broadly used by the molecular, genetics, and bioinformatics communities, there is currently no single, widely accepted set of versatile, but standardized data tools for the remote sensing community, greatly hampering advances in this area. While rudimentary online spectral libraries for vegetation are available, most of these cannot easily accommodate large volumes of spectral time series or image data. Most 
existing spectral libraries focus on a few static types (the archetypal mean). However, for functional analysis, we are often more interested in the variation over time and space (variance), which is not easily accommodated in current databases. While image databases exist for most satellite sensors, there is no similar community database or archival solution for the variety of current and emerging airborne or field imaging spectrometers, hampering our sharing and understanding of imaging spectroscopy for addressing plant function in a broader context. Both basic research and emerging applications, including phenotyping and precision farming, would greatly benefit from effective data management and processing solutions, which remain sparse to date. Examples include the SPECCHIO database (Hueni et al. 2009, 2011). The terrestrial remote sensing community could learn from other disciplines (e.g., astrophysics), where effective community solutions for handling and sharing large spectral datasets have been developed (Munari et al. 2005; Rayner et al. 2009).

\section{Societal Benefits and Global Challenges}

Further development of remote sensing tools for vegetation functional assessment would provide multiple benefits, both to basic science and to society. Vegetation plays a key role in many global Earth system processes, ranging from biogeochemical cycles to the surface-atmosphere transport of mass and energy that regulates our atmosphere and climate. Vegetation also supports diverse biological communities and provides many essential ecosystem goods and services. Until we can reliably monitor vegetation function at all scales, we cannot fully understand these processes and contributions or how they are changing. For example, longstanding questions about the role of the terrestrial biosphere as a carbon sink, and whether we should expect that sink to start relaxing, thereby accelerating climate change (Schimel 2007) could be better answered with improved remote sensing tools for addressing vegetation function. Similarly, remote sensing offers promising new and integrative ways of assessing biodiversity (Cavender-Bares et al. 2017), species composition (Asner and Vitousek 2005), and emerging diseases (Calderón et al. 2013; Zarco-Tejada et al. 2018) in a changing world. Many promising applications and management practices, including phenotyping, precision agriculture, and early stress and disease detection, could be better addressed with well-designed optical remote sensing methods geared toward accurate, precise, and timely vegetation monitoring and related analytics tools. Development of novel imaging spectroscopy-based remote sensing methods for vegetation function will be essential for monitoring and maintaining healthy and resilient ecosystems in changing world, providing concurrent social and economic benefits.

Acknowledgements The authors wish to thank the International Space Science Institute (ISSI) for a stimulating meeting that led to this paper, and three reviewers whose insightful comments and suggestions improved the manuscript. Donnette Thayer assisted with Fig. 1 and Ran Wang with Fig. 2. Data presented in Fig. 2 were collected with support from the National Sciences and Engineering Research Council of Canada (NSERC) and The Canadian Foundation for Innovation (CFI) funding to J. Gamon. Z. Malenovský was supported by the Australian Research Council Future Fellowship: Bridging scales in remote sensing of vegetation stress (FT160100477). The contribution of M.E. Schaepman is supported by the University of Zurich Research Priority Program on Global Change and Biodiversit (URPP GCB). The contribution of B. Somers (Katholieke Universiteit Leuven) is supported by the Belgian Science Policy Office in the framework of the STEREOIII program (projects: SR/00/307, SR/01/349, SR/00/363).

OpenAccess This article is distributed under the terms of the Creative Commons Attribution 4.0 International License (http://creativecommons.org/licenses/by/4.0/), which permits unrestricted use, distribution, 
and reproduction in any medium, provided you give appropriate credit to the original author(s) and the source, provide a link to the Creative Commons license, and indicate if changes were made.

\section{References}

Amato U, Antoniadis A, Carfora MF, Colandrea P, Cuomo V, Franzese M, Pignatti S, Serio C (2013) Statistical classification for assessing PRISMA hyperspectral potential for agricultural land use. IEEE J Sel Top Appl Earth Observ Remote Sens 6:615-625

Arora V (2002) Modeling vegetation as a dynamic component in soil-vegetation-atmosphere transfer schemes and hydrological models. Rev Geophys. https://doi.org/10.1029/2001rg000103

Aschbacher J, Milagro-Pérez MP (2012) The European Earth monitoring (GMES) programme: status and perspectives. Remote Sens Environ 120:3-8

Asner GP, Martin RE (2016) Spectranomics: emerging science and conservation opportunities at the interface of biodiversity and remote sensing. Glob Ecol Conserv 8:212-219. https://doi.org/10.1016/j. gecco.2016.09.010

Asner GP, Vitousek PM (2005) Remote analysis of biological invasion and biogeochemical change. Proc Natl Acad Sci USA 102:4383-4386. https://doi.org/10.1073/pnas.0500823102

Asner GP, Brodrick PG, Anderson CB, Vaughn N, Knapp DE, Martin RE (2016a) Progressive forest canopy water loss during the 2012-2015 California drought. Proc Natl Acad Sci USA 113:E249-E255. https ://doi.org/10.1073/pnas.1523397113

Asner GP, Knapp DE, Anderson CB, Martin RE, Vaughn N (2016b) Large-scale climatic and geophysical controls on the leaf economics spectrum. Proc Natl Acad Sci USA 113:E4043-E4051. https://doi. org/10.1073/pnas.1604863113

Badgley G, Field CB, Berry JA (2017) Canopy near-infrared reflectance and terrestrial photosynthesis. Sci Adv 3:5. https://doi.org/10.1126/sciadv.1602244

Balzarolo M et al (2011) Ground-based optical measurements at European flux sites: a review of methods, instruments and current controversies. Sensors 11:7954-7981. https://doi.org/10.3390/s110807954

Barton CVM, North PRJ (2001) Remote sensing of canopy light use efficiency using the photochemical reflectance index-model and sensitivity analysis. Remote Sens Environ 78:264-273. https://doi. org/10.1016/s0034-4257(01)00224-3

Battaglia M, Cherry ML, Beadle CL, Sands PJ, Hingston A (1998) Prediction of leaf area index in eucalypt plantations: effects of water stress and temperature. Tree Physiol 18:521-528

Bloom AJ, Chapin FS, Mooney HA (1985) Resource limitation in plants-an economic analogy. Annu Rev Ecol Syst 16:363-392. https://doi.org/10.1146/annurev.es.16.110185.002051

Bonan GB, Levis S, Kergoat L, Oleson KW (2002) Landscapes as patches of plant functional types: an integrating concept for climate and ecosystem models. Glob Biogeochem Cycles. https://doi. org/10.1029/2000gb001360

Bonan GB, Levis S, Sitch S, Vertenstein M, Oleson KW (2003) A dynamic global vegetation model for use with climate models: concepts and description of simulated vegetation dynamics. Glob Change Biol 9:1543-1566. https://doi.org/10.1046/j.1365-2486.2003.00681.x

Braun D et al (2017) From instantaneous to continuous: using imaging spectroscopy and in situ data to map two productivity-related ecosystem services. Ecol Indic 82:409-419. https://doi.org/10.1016/j.ecoli nd.2017.06.045

Burkart A, Cogliati S, Schickling A, Rascher U (2014) A novel UAV-based ultra-light weight spectrometer for field spectroscopy. IEEE Sens J 14:62-67. https://doi.org/10.1109/jsen.2013.2279720

Burkart A et al (2015) A method for uncertainty assessment of passive sun-induced chlorophyll fluorescence retrieval using an infrared reference light. IEEE Sens J 15:4603-4611. https://doi.org/10.1109/ jsen.2015.2422894

Calderón R, Navas-Cortés JA, Lucena C, Zarco-Tejada PJ (2013) High-resolution airborne hyperspectral and thermal imagery for early detection of Verticillium wilt of olive using fluorescence, temperature and narrow-band spectral indices. Remote Sens Environ 139:231-245. https://doi.org/10.1016/j. rse.2013.07.031

Campbell PKE et al (2013) EO-1 hyperion reflectance time series at calibration and validation sites: stability and sensitivity to seasonal dynamics. IEEE J Sel Top Appl Earth Obs Remote Sens 6:276-290. https://doi.org/10.1109/jstars.2013.2246139 
Cavender-Bares J, Gamon JA, Hobbie SE, Madritch MD, Meireles JE, Schweiger AK, Townsend PA (2017) Harnessing plant spectra to integrate the biodiversity sciences across biological and spatial scales. Am J Bot 104:966-969. https://doi.org/10.3732/ajb.1700061

Chavana-Bryant C et al (2017) Leaf aging of Amazonian canopy trees as revealed by spectral and physiochemical measurements. New Phytol 214:1049-1063. https://doi.org/10.1111/nph.13853

Cornelissen JHC et al (2003) A handbook of protocols for standardised and easy measurement of plant functional traits worldwide. Aust J Bot 51:335-380. https://doi.org/10.1071/bt02124

de Wit CT (1970) Dynamic concepts in biology. In: Setlik I (ed) Prediction and measurement of photosynthetic productivity. Centre for Agricultural Publishing and Documentation, Wageningen, pp 17-23

DeFries RS, Townshend JRG (1994) NDVI-derived land cover classifications at a global scale. Int J Remote Sens 15:3567-3586

Donlon C et al (2012) The global monitoring for environment and security (GMES) Sentinel-3 mission. Remote Sens Environ 120:37-57. https://doi.org/10.1016/j.rse.2011.07.024

Drolet GG et al (2008) Regional mapping of gross light-use efficiency using MODIS spectral indices. Remote Sens Environ 112:3064-3078. https://doi.org/10.1016/j.rse.2008.03.002

Drusch M et al (2012) Sentinel-2: ESA's optical high-resolution mission for GMES operational services. Remote Sens Environ 120:25-36. https://doi.org/10.1016/j.rse.2011.11.026

Drusch M et al (2017) The FLuorescence EXplorer Mission Concept-ESA's Earth Explorer 8. IEEE Trans Geosci Remote Sens 55:1273-1284. https://doi.org/10.1109/tgrs.2016.2621820

Eckardt A et al (2015) DESIS (DLR Earth Sensing Imaging Spectrometer for the ISS-MUSES platform). In: 2015 IEEE international geoscience and remote sensing symposium (IGARSS), pp 1457-1459

Ehleringer JR, Comstock J (1987) Leaf absorptance and leaf angle: mechanisms for stress avoidance. In: Tenhunen JD, Catarino FM, Lange OL, Oechel WC (eds) Plant response to stress: functional analysis in Mediterranean ecosystems. Springer, Berlin, pp 55-76

Ehleringer JR, Field CB (1993) Scaling physiological processes: leaf to globe, 1st edn. Academic Press, New York

Enquist BJ et al (2015) Scaling from traits to ecosystems: developing a general trait driver theory via integrating trait-based and metabolic scaling theories. In: Pawar S, Woodward G, Dell AI (eds) Advances in ecological research, vol 52. Academic Press, New York, pp 249-318. https://doi. org/10.1016/bs.aecr.2015.02.001

Feilhauer H, Somers B, van der Linden S (2017) Optical trait indicators for remote sensing of plant species composition: predictive power and seasonal variability. Ecol Indic 73:825-833. https://doi. org/10.1016/j.ecolind.2016.11.003

Feret JB, Asner GP (2014) Mapping tropical forest canopy diversity using high-fidelity imaging spectroscopy. Ecol Appl 24:1289-1296

Field CB (1991) Ecological scaling of carbon gain to stress and resource availability. In: Mooney HA, Winner WE, Pell EJ (eds) Response of plants to multiple stresses. Physiological ecology. Academic Press, New York, pp 35-65

Frankenberg C et al (2011) New global observations of the terrestrial carbon cycle from GOSAT: patterns of plant fluorescence with gross primary productivity. Geophys Res Lett 38:6. https://doi. org/10.1029/2011g1048738

Fuentes DA et al (2006) Mapping carbon and water vapor fluxes in a chaparral ecosystem using vegetation indices derived from AVIRIS. Remote Sens Environ 103:312-323. https://doi.org/10.1016/j. rse.2005.10.028

Gamon JA (2015) Reviews and syntheses: optical sampling of the flux tower footprint. Biogeosciences 12:4509-4523. https://doi.org/10.5194/bg-12-4509-2015

Gamon JA, Surfus JS (1999) Assessing leaf pigment content and activity with a reflectometer. New Phytol 143:105-117. https://doi.org/10.1046/j.1469-8137.1999.00424.x

Gamon JA, Qiu HL (1999) Ecological applications of remote sensing at multiple scales. In: Pugnaire F, Valladares F (eds) Handbook of functional plant ecology. Marcel Dekker Inc., New York, pp $805-846$

Gamon JA, Serrano L, Surfus JS (1997) The photochemical reflectance index: an optical indicator of photosynthetic radiation use efficiency across species, functional types, and nutrient levels. Oecologia 112:492-501. https://doi.org/10.1007/s004420050337

Gamon JA, Field CB, Fredeen AL, Thayer S (2001) Assessing photosynthetic downregulation in sunflower stands with an optically-based model. Photosynth Res 67:113-125. https://doi. org/10.1023/a:1010677605091

Gamon JA, Cheng YF, Claudio H, MacKinney L, Sims DA (2006) A mobile tram system for systematic sampling of ecosystem optical properties. Remote Sens Environ 103:246-254. https://doi. org/10.1016/j.rse.2006.04.006 
Gamon JA et al (2010) SpecNet revisited: bridging flux and remote sensing communities. Can J Remote Sens 36:S376-S390

Gamon JA, Huemmrich KF, Stone RS, Tweedie CE (2013) Spatial and temporal variation in primary productivity (NDVI) of coastal Alaskan tundra: decreased vegetation growth following earlier snowmelt. Remote Sens Environ 129:144-153. https://doi.org/10.1016/j.rse.2012.10.030

Gamon JA et al (2016) A remotely sensed pigment index reveals photosynthetic phenology in evergreen conifers. Proc Natl Acad Sci USA 113:13087-13092. https://doi.org/10.1073/pnas.1606162113

Garbulsky MF, Peñuelas J, Papale D, Filella I (2008) Remote estimation of carbon dioxide uptake by a Mediterranean forest. Glob Change Biol 14:2860-2867. https://doi.org/10.111 1/j.1365-2486.2008.01684.x

Garonna I, de Jong R, Schaepman ME (2016) Variability and evolution of global land surface phenology over the past three decades (1982-2012). Glob Change Biol 22:1456-1468. https://doi. org/10.1111/gcb. 13168

Gastellu-Etchegorry JP et al (2017) DART: recent advances in remote sensing data modeling with atmosphere, polarization, and chlorophyll fluorescence. IEEE J Sel Top Appl Earth Obs Remote Sens 10:2640-2649. https://doi.org/10.1109/jstars.2017.2685528

Gitelson AA, Viña A, Ciganda V, Rundquist DC, Arkebauer TJ (2005) Remote estimation of canopy chlorophyll content in crops. Geophys Res Lett 32:L08403. https://doi.org/10.1029/2005g1022688

Gitelson AA, Gamon JA, Solovchenko A (2017) Multiple drivers of seasonal change in PRI: Implications for photosynthesis 2. Stand level. Remote Sens Environ 190:198-206. https://doi.org/10.1016/j. rse.2016.12.015

Goerner A, Reichstein M, Rambal S (2009) Tracking seasonal drought effects on ecosystem light use efficiency with satellite-based PRI in a Mediterranean forest. Remote Sens Environ 113:1101-1111. https://doi.org/10.1016/j.rse.2009.02.001

Goetz SJ, Bunn AG, Fiske GJ, Houghton RA (2005) Satellite-observed photosynthetic trends across boreal North America associated with climate and fire disturbance. Proc Natl Acad Sci USA 102:1352113525. https://doi.org/10.1073/pnas.0506179102

Grime JP (2006) Plant strategies, vegetation processes, and ecosystem properties. Wiley, New York

Guanter L et al (2012) Retrieval and global assessment of terrestrial chlorophyll fluorescence from GOSAT space measurements. Remote Sens Environ 121:236-251. https://doi.org/10.1016/j.rse.2012.02.006

Guanter L et al (2015a) The EnMAP spaceborne imaging spectroscopy mission for earth observation. Remote Sens 7:8830-8857. https://doi.org/10.3390/rs70708830

Guanter L et al (2015b) Potential of the TROPOspheric Monitoring Instrument (TROPOMI) onboard the Sentinel-5 Precursor for the monitoring of terrestrial chlorophyll fluorescence. Atmos Meas Tech 8:1337-1352. https://doi.org/10.5194/amt-8-1337-2015

Heinsch FA et al (2006) Evaluation of remote sensing based terrestrial productivity from MODIS using regional tower eddy flux network observations. IEEE Trans Geosci Remote Sens 44:1908-1925. https ://doi.org/10.1109/tgrs.2005.853936

Hilker T, Coops NC, Hall FG, Black TA, Wulder MA, Nesic Z, Krishnan P (2008) Separating physiologically and directionally induced changes in PRI using BRDF models. Remote Sens Environ 112:27772788. https://doi.org/10.1016/j.rse.2008.01.011

Hilker T, Gitelson A, Coops NC, Hall FG, Black TA (2011) Tracking plant physiological properties from multi-angular tower-based remote sensing. Oecologia 165:865-876. https://doi.org/10.1007/s0044 2-010-1901-0

Homolová L, Malenovský Z, Clevers J, Garcia-Santos G, Schaepman ME (2013) Review of optical-based remote sensing for plant trait mapping. Ecol Complex 15:1-16. https://doi.org/10.1016/j.ecoco m.2013.06.003

Homolová L, Schaepman ME, Lamarque P, Clevers J, de Bello F, Thuiller W, Lavorel S (2014) Comparison of remote sensing and plant trait-based modelling to predict ecosystem services in subalpine grasslands. Ecosphere. https://doi.org/10.1890/es13-00393.1

Huemmrich KF, Gamon JA, Tweedie CE, Campbell PKE, Landis DR, Middleton EM (2013) Arctic tundra vegetation functional types based on photosynthetic physiology and optical properties. IEEE J Sel Top Appl Earth Obs Remote Sens 6:265-275. https://doi.org/10.1109/jstars.2013.2253446

Huemmrich KF, Campbell PKE, Gao BC, Flanagan LB, Goulden M (2017) ISS as a platform for optical remote sensing of ecosystem carbon fluxes: a case study using HICO. IEEE J Sel Top Appl Earth Obs Remote Sens 10:4360-4375. https://doi.org/10.1109/jstars.2017.2725825

Hueni A, Nieke J, Schopfer J, Kneubühler M, Itten K (2009) The spectral database SPECCHIO for improved long term usability and data sharing. Comput Geosci 35(3):557-565. https://doi.org/10.1016/j.cageo .2008 .03 .015 
Hueni A, Malthus T, Kneubuehler M, Schaepman M (2011) Data exchange between distributed spectral databases. Comput Geosci 37:861-873. https://doi.org/10.1016/j.cageo.2010.12.009

Huete A, Didan K, Miura T, Rodriguez EP, Gao X, Ferreira LG (2002) Overview of the radiometric and biophysical performance of the MODIS vegetation indices. Remote Sens Environ 83:195-213. https ://doi.org/10.1016/s0034-4257(02)00096-2

Jacquemoud S, Baret F (1990) PROSPECT: a model of leaf optical properties spectra. Remote Sens Environ 34:75-91. https://doi.org/10.1016/0034-4257(90)90100-z

Jacquemoud S et al (2009) PROSPECT plus SAIL models: a review of use for vegetation characterization. Remote Sens Environ 113:S56-S66. https://doi.org/10.1016/j.rse.2008.01.026

Jarvis P (1993) Prospects for bottom up models. In: Ehleringer JR, Field CB (eds) Scaling physiological processes: leaf to globe, 1st edn. Academic Press, New York, pp 115-126

Joiner J, Yoshida Y, Vasilkov AP, Yoshida Y, Corp LA, Middleton EM (2011) First observations of global and seasonal terrestrial chlorophyll fluorescence from space. Biogeosciences 8:637-651. https://doi. org/10.5194/bg-8-637-2011

Jung M et al (2011) Global patterns of land-atmosphere fluxes of carbon dioxide, latent heat, and sensible heat derived from eddy covariance, satellite, and meteorological observations. J Geophys Res Biogeosci. https://doi.org/10.1029/2010jg001566

Kampe TU, Johnson BR, Kuester M, Keller M (2010) NEON: the first continental-scale ecological observatory with airborne remote sensing of vegetation canopy biochemistry and structure. J Appl Remote Sens. https://doi.org/10.1117/1.3361375

Kattenborn T, Fassnacht FE, Pierce S, Lopatin J, Grime JP, Schmidtlein S (2017) Linking plant strategies and plant traits derived by radiative transfer modelling. J Veg Sci 28:717-727. https://doi. org/10.1111/jvs.12525

Kattge J et al (2011) TRY - a global database of plant traits. Glob Change Biol 17:2905-2935. https:// doi.org/10.1111/j.1365-2486.2011.02451.x

Knyazikhin Y et al (2013) Hyperspectral remote sensing of foliar nitrogen content. Proc Natl Acad Sci USA 110:E185-E192. https://doi.org/10.1073/pnas.1210196109

Kraft S et al (2013) FLORIS: phase A status of the fluorescence imaging spectrometer of the Earth Explorer mission candidate FLEX. In: Conference on sensors, systems, and next-generation satellites XVII, Dresden, Germany, 23-26 Sept 2013. Proceedings of SPIE. https://doi. org/10.1117/12.2032060

Lee CM, Cable ML, Hook SJ, Green RO, Ustin SL, Mandl DJ, Middleton EM (2015) An introduction to the NASA Hyperspectral InfraRed Imager (HyspIRI) mission and preparatory activities. Remote Sens Environ 167:6-19. https://doi.org/10.1016/j.rse.2015.06.012

Levin SA (1992) The problem of pattern and scale in ecology. Ecology 73:1943-1967. https://doi. org/10.2307/1941447

Lucieer A, Malenovsky Z, Veness T, Wallace L (2014) HyperUAS-Imaging spectroscopy from a multirotor unmanned aircraft system. J Field Robot 31:571-590. https://doi.org/10.1002/rob.21508

Lyapustin A, Martonchik J, Wang Y, Laszlo I, Korkin S (2011a) Multiangle implementation of atmospheric correction (MAIAC): 1. Radiative transfer basis and look-up tables. J Geophys Res Atmos. https://doi.org/10.1029/2010jd014985

Lyapustin A et al (2011b) Multiangle implementation of atmospheric correction (MAIAC): 2. Aerosol algorithm. J Geophys Res Atmos. https://doi.org/10.1029/2010jd014986

Malenovský Z, Albrechtova J, Lhotakova Z, Zurita-Milla R, Clevers J, Schaepman ME, Cudlin P (2006) Applicability of the PROSPECT model for Norway spruce needles. Int J Remote Sens 27:53155340. https://doi.org/10.1080/01431160600762990

Malenovský Z, Rott H, Cihlar J, Schaepman ME, Garcia-Santos G, Fernandes R, Berger M (2012) Sentinels for science: potential of Sentinel-1, -2, and -3 missions for scientific observations of ocean, cryosphere, and land. Remote Sens Environ 120:91-101. https://doi.org/10.1016/j.rse.2011.09.026

Malenovský Z et al (2013) Retrieval of spruce leaf chlorophyll content from airborne image data using continuum removal and radiative transfer. Remote Sens Environ 131:85-102. https://doi. org/10.1016/j.rse.2012.12.015

Malenovský Z, Lucieer A, King DH, Turnbull JD, Robinson SA (2017) Unmanned aircraft system advances health mapping of fragile polar vegetation. Methods Ecol Evol 8:1842-1857. https://doi. org/10.1111/2041-210x.12833

Malenovský Z, Homolová L, Lukeš P, Buddenbaum H, Verrelst J, Alonso L, Schaepman ME, Lauret N, Gastellu-Etchegorry JP (2019) Variability and uncertainty challenges in upscaling imaging spectroscopy observations from leaves to vegetation canopies. Surv Geophys (in review; this issue)

Marshall E (1993) Global change-fitting planet earth into a user-friendly database. Science 261:846. https://doi.org/10.1126/science.261.5123.846 
Middleton EM, Cheng Y-B, Hilker T, Black TA, Krishnan P, Coops NC, Huemmrich KF (2009) Linking foliage spectral responses to canopy-level ecosystem photosynthetic light-use efficiency at a Douglas-fir forest in Canada. Can J Remote Sens 35:166-188

Middleton EM, Huemmrich KF, Landis DR, Black TA, Barr AG, McCaughey JH (2016) Photosynthetic efficiency of northern forest ecosystems using a MODIS-derived Photochemical Reflectance Index (PRI). Remote Sens Environ 187:345-366. https://doi.org/10.1016/j.rse.2016.10.021

Middleton EM et al (2017) The 2013 FLEX-US airborne campaign at the Parker Tract loblolly pine plantation in North Carolina, USA. Remote Sens. https://doi.org/10.3390/rs9060612

Munari U, Sordo R, Castelli F, Zwitter T (2005) An extensive library of 2500-10500 А synthetic spectra. Astron Astrophys 442:1127-1134. https://doi.org/10.1051/0004-6361:20042490

Myneni RB et al (2002) Global products of vegetation leaf area and fraction absorbed PAR from year one of MODIS data. Remote Sens Environ 83:214-231. https://doi.org/10.1016/s0034-4257(02)00074-3

Ollinger SV (2011) Sources of variability in canopy reflectance and the convergent properties of plants. New Phytol 189:375-394. https://doi.org/10.1111/j.1469-8137.2010.03536.x

Ollinger SV et al (2008) Canopy nitrogen, carbon assimilation, and albedo in temperate and boreal forests: functional relations and potential climate feedbacks. Proc Natl Acad Sci USA 105:1933619341. https://doi.org/10.1073/pnas.0810021105

Pavlick R, Drewry DT, Bohn K, Reu B, Kleidon A (2013) The Jena Diversity-Dynamic Global Vegetation Model (JeDi-DGVM): a diverse approach to representing terrestrial biogeography and biogeochemistry based on plant functional trade-offs. Biogeosciences 10:4137-4177. https://doi.org/10.5194/ bg-10-4137-2013

Pinto F et al (2016) Sun-induced chlorophyll fluorescence from high-resolution imaging spectroscopy data to quantify spatio-temporal patterns of photosynthetic function in crop canopies. Plant, Cell Environ 39:1500-1512. https://doi.org/10.1111/pce.12710

Pinto F, Müller-Linow M, Schickling A, Cendrero-Mateo MP, Ballvora A, Rascher U (2017) Multiangular observation of canopy sun-induced chlorophyll fluorescence combining imaging spectroscopy and stereoscopy. Remote Sens 9, article no. 415. https://doi.org/10.3390/rs9050415

Porcar-Castell A et al (2014) Linking chlorophyll a fluorescence to photosynthesis for remote sensing applications: mechanisms and challenges. J Exp Bot 65:4065-4095. https://doi.org/10.1093/jxb/eru191

Quattrochi DA, Goodchild MF (1997) Scale in remote sensing and GIS. CRC Press, Boca Raton

Rahman AF, Cordova VD, Gamon JA, Schmid HP, Sims DA (2004) Potential of MODIS ocean bands for estimating $\mathrm{CO}_{2}$ flux from terrestrial vegetation: a novel approach. Geophys Res Lett. https://doi. org/10.1029/2004g1019778

Rascher U et al (2015) Sun-induced fluorescence - a new probe of photosynthesis: first maps from the imaging spectrometer. HyPlant Glob Change Biol 21:4673-4684. https://doi.org/10.1111/gcb.13017

Rayner JT, Cushing MC, Vacca WD (2009) The infrared telescope facility (IRTF) spectral library: cool stars. Astrophys J Suppl 185:289-432. https://doi.org/10.1088/0067-0049/185/2/289

Reich PB, Ellsworth DS, Walters MB (1998) Leaf structure (specific leaf area) modulates photosynthesis-nitrogen relations: evidence from within and across species and functional groups. Funct Ecol 12:948-958. https://doi.org/10.1046/j.1365-2435.1998.00274.x

Roelofsen HD, van Bodegom PM, Kooistra L, Witte JPM (2014) Predicting leaf traits of herbaceous species from their spectral characteristics. Ecol Evol 4:706-719. https://doi.org/10.1002/ece3.932

Rossini M et al (2015) Red and far red Sun-induced chlorophyll fluorescence as a measure of plant photosynthesis. Geophys Res Lett 42:1632-1639. https://doi.org/10.1002/2014g1062943

Rouse JW, Haas RH, Schell JA, Deering DW (1974) Monitoring vegetation systems in the Great Plains with ERTS. Remote Sensing Center, Texas A\&M University, College Station

Running SW, Nemani RR, Heinsch FA, Zhao MS, Reeves M, Hashimoto H (2004) A continuous satellite-derived measure of global terrestrial primary production. Bioscience 54:547-560. https://doi. org/10.1641/0006-3568(2004)054\%5b0547:acsmog\%5d2.0.co;2

Schaepman ME et al (2015) Advanced radiometry measurements and earth science applications with the Airborne Prism Experiment (APEX). Remote Sens Environ 158:207-219. https://doi.org/10.1016/j. rse.2014.11.014

Schimel D (2007) Carbon cycle conundrums. Proc Natl Acad Sci USA 104:18353-18354. https://doi. org/10.1073/pnas.0709331104

Schneider FD, Letterer R, Morsdorf F, Gastellu-Etchegorry JP, Lauret N, Pfeifer N, Schaepman ME (2014) Simulating imaging spectrometer data: 3D forest modeling based on LiDAR and in situ data. Remote Sens Environ 152:235-250. https://doi.org/10.1016/j.rse.2014.06.015

Schneider FD, Morsdorf F, Schmid B, Petchey OL, Hueni A, Schimel DS, Schaepman ME (2017) Mapping functional diversity from remotely sensed morphological and physiological forest traits. Nat Commun. https://doi.org/10.1038/s41467-017-01530-3 
Schull MA, Anderson MC, Houborg R, Gitelson A, Kustas WP (2015) Thermal-based modeling of coupled carbon, water, and energy fluxes using nominal light use efficiencies constrained by leaf chlorophyll observations. Biogeosciences 12:1511-1523. https://doi.org/10.5194/bg-12-1511-2015

Schweiger AK, Schütz M, Risch AC, Kneubühler M, Haller R, Schaepman ME (2017) How to predict plant functional types using imaging spectroscopy: linking vegetation community traits, plant functional types and spectral response. Methods Ecol Evol 8:86-95. https://doi.org/10.1111/2041-210x.12642

Schweiger AK et al (2018) Plant spectral diversity integrates functional and phylogenetic components of biodiversity and predicts ecosystem function. Nat Ecol Evol 2:976. https://doi.org/10.1038/s4155 9-018-0551-1

Sellers PJ et al (1996a) Comparison of radiative and physiological effects of doubled atmospheric $\mathrm{CO}_{2}$ on climate. Science 271:1402-1406. https://doi.org/10.1126/science.271.5254.1402

Sellers PJ, Los SO, Tucker CJ, Justice CO, Dazlich DA, Collatz GJ, Randall DA (1996b) A revised land surface parameterization (SiB2) for atmospheric GCMs. Part II: the generation of global fields of terrestrial biophysical parameters from satellite data. J Clim 9:706-737. https://doi.org/10.1175/15200442(1996)009\%3c0706:arlspf\%3e

Sellers PJ et al (1997) BOREAS in 1997: experiment overview, scientific results, and future directions. J Geophys Res Atmos 102:28731-28769. https://doi.org/10.1029/97jd03300

Serbin SP, Dillaway DN, Kruger EL, Townsend PA (2012) Leaf optical properties reflect variation in photosynthetic metabolism and its sensitivity to temperature. J Exp Bot 63:489-502. https://doi. org/10.1093/jxb/err294

Serbin SP, Singh A, McNeil BE, Kingdon CC, Townsend PA (2014) Spectroscopic determination of leaf morphological and biochemical traits for northern temperate and boreal tree species. Ecol Appl 24:1651-1669

Serbin SP et al (2015) Remotely estimating photosynthetic capacity, and its response to temperature, in vegetation canopies using imaging spectroscopy. Remote Sens Environ 167:78-87. https://doi. org/10.1016/j.rse.2015.05.024

Serrano L, Ustin SL, Roberts DA, Gamon JA, Peñuelas J (2000) Deriving water content of chaparral vegetation from AVIRIS data. Remote Sens Environ 74:570-581. https://doi.org/10.1016/s0034 $-4257(00) 00147-4$

Simmer C et al (2015) Monitoring and modeling the terrestrial system from pores to catchments: the transregional collaborative research center on patterns in the soil-vegetation-atmosphere system. Bull Am Meteorol 96:1765-1787. https://doi.org/10.1175/bams-d-13-00134.1

Sims DA, Gamon JA (2003) Estimation of vegetation water content and photosynthetic tissue area from spectral reflectance: a comparison of indices based on liquid water and chlorophyll absorption features. Remote Sens Environ 84:526-537. https://doi.org/10.1016/s0034-4257(02)00151-7

Sims DA, Luo HY, Hastings S, Oechel WC, Rahman AF, Gamon JA (2006) Parallel adjustments in vegetation greenness and ecosystem $\mathrm{CO}_{2}$ exchange in response to drought in a Southern California chaparral ecosystem. Remote Sens Environ 103:289-303. https://doi.org/10.1016/j. rse.2005.01.020

Singh A, Serbin SP, McNeil BE, Kingdon CC, Townsend PA (2015) Imaging spectroscopy algorithms for mapping canopy foliar chemical and morphological traits and their uncertainties. Ecol Appl 25:2180-2197. https://doi.org/10.1890/14-2098.1.sm

Somers B, Asner GP (2012) Hyperspectral time series analysis of native and invasive species in Hawaiian rainforests. Remote Sens 4:2510-2529. https://doi.org/10.3390/rs4092510

Somers B, Asner GP, Martin RE, Anderson CB, Knapp DE, Wright SJ, Van De Kerchove R (2015) Mesoscale assessment of changes in tropical tree species richness across a bioclimatic gradient in Panama using airborne imaging spectroscopy. Remote Sens Environ 167:111-120. https://doi. org/10.1016/j.rse.2015.04.016

Springer KR, Wang R, Gamon JA (2017) Parallel seasonal patterns of photosynthesis, fluorescence, and reflectance indices in boreal trees. Remote Sens. https://doi.org/10.3390/rs9070691

Street LE, Shaver GR, Williams M, Van Wijk MT (2007) What is the relationship between changes in canopy leaf area and changes in photosynthetic $\mathrm{CO}_{2}$ flux in arctic ecosystems? J Ecol 95:139-150. https://doi.org/10.1111/j.1365-2745.2006.01187.x

Stylinski CD, Gamon JA, Oechel WC (2002) Seasonal patterns of reflectance indices, carotenoid pigments and photosynthesis of evergreen chaparral species. Oecologia 131:366-374. https://doi. org/10.1007/s00442-002-0905-9

Teuling AJ, Seneviratne SI (2008) Contrasting spectral changes limit albedo impact on land-atmosphere coupling during the 2003 European heat wave. Geophys Res Lett. https://doi.org/10.1029/2007g 1032778 
Timmermans J, Su Z, van der Tol C, Verhoef A, Verhoef W (2013) Quantifying the uncertainty in estimates of surface-atmosphere fluxes through joint evaluation of the SEBS and SCOPE models. Hydrol Earth Syst Sci 17:1561-1573. https://doi.org/10.5194/hess-17-1561-2013

Townsend PA, Serbin SP, Kruger EL, Gamon JA (2013) Disentangling the contribution of biological and physical properties of leaves and canopies in imaging spectroscopy data. Proc Natl Acad Sci USA 110:E1074-E1074. https://doi.org/10.1073/pnas.1300952110

Tucker CJ (1979) Red and photographic infrared linear combinations for monitoring vegetation. Remote Sens Environ 8:127-150. https://doi.org/10.1016/0034-4257(79)90013-0

Tucker CJ, Townshend JRG, Goff TE (1985) African land-cover classification using satellite data. Science 227:369-375. https://doi.org/10.1126/science.227.4685.369

Ustin SL, Gamon JA (2010) Remote sensing of plant functional types. New Phytol 186:795-816. https:// doi.org/10.1111/j.1469-8137.2010.03284.x

Ustin SL, Gitelson AA, Jacquemoud S, Schaepman M, Asner GP, Gamon JA, Zarco-Tejada P (2009) Retrieval of foliar information about plant pigment systems from high resolution spectroscopy. Remote Sens Environ 113:S67-S77. https://doi.org/10.1016/j.rse.2008.10.019

van Bodegom PM, Douma JC, Verheijen LM (2014) A fully traits-based approach to modeling global vegetation distribution. Proc Natl Acad Sci USA 111:13733-13738. https://doi.org/10.1073/ pnas. 1304551110

van der Tol C, Verhoef W, Timmermans J, Verhoef A, Su Z (2009) An integrated model of soil-canopy spectral radiances, photosynthesis, fluorescence, temperature and energy balance. Biogeosciences 6:3109-3129. https://doi.org/10.5194/bg-6-3109-2009

Verhoef W (1984) Light scattering by leaf layers with application to canopy reflectance modeling: the SAIL model. Remote Sens Environ 16:125-141. https://doi.org/10.1016/0034-4257(84)90057-9

Verrelst J et al (2019) Quantifying vegetation biophysical variables from imaging spectroscopy data: a review on retrieval methods. Surv Geophys 1-41. https://doi.org/10.1007/s10712-018-9478-y (this issue)

Verrelst J, Dethier S, Rivera JP, Munoz-Mari J, Camps-Valls G, Moreno J (2016) Active learning methods for efficient hybrid biophysical variable retrieval. IEEE Geosci Remote Sens Lett 13:1012-1016. https ://doi.org/10.1109//grs.2016.2560799

Wang WM, Li ZL, Su HB (2007) Comparison of leaf angle distribution functions: effects on extinction coefficient and fraction of sunlit foliage. Agric For Meteorol 143:106-122. https://doi.org/10.1016/j. agrformet.2006.12.003

Wang R, Gamon JA, Emmerton CA, Haitao L, Nestola E, Pastorello GZ, Menzer O (2016a) Integrated analysis of productivity and biodiversity in a southern Alberta prairie. Remote Sens. https://doi. org/10.3390/rs8030214

Wang $\mathrm{R}$ et al (2016b) Seasonal variation in the NDVI-species richness relationship in a prairie grassland experiment (Cedar Creek). Remote Sens 8:1. https://doi.org/10.3390/rs8020128

Wieneke S, Ahrends H, Damm A, Pinto F, Stadler A, Rossini M, Rascher U (2016) Airborne based spectroscopy of red and far-red sun-induced chlorophyll fluorescence: implications for improved estimates of gross primary productivity. Remote Sens Environ 184:654-667. https://doi.org/10.1016/j. rse.2016.07.025

Williamson SN, Barrio IC, Hik DS, Gamon JA (2016) Phenology and species determine growing-season albedo increase at the altitudinal limit of shrub growth in the sub-Arctic. Glob Change Biol 22:36213631. https://doi.org/10.1111/gcb.13297

Wright IJ et al (2004) The worldwide leaf economics spectrum. Nature 428:821-827. https://doi. org/10.1038/nature02403

Wyber R, Malenovský Z, Ashcroft MB, Osmond B, Robinson SA (2017) Do daily and seasonal trends in leaf solar induced fluorescence reflect changes in photosynthesis, growth or light exposure? Remote Sens. https://doi.org/10.3390/rs9060604

Zarco-Tejada PJ et al (2018) Previsual symptoms of Xylella fastidiosa infection revealed in spectral planttrait alterations. Nat Plants 4:432-439. https://doi.org/10.1038/s41477-018-0189-7

Zhang QY, Middleton EM, Margolis HA, Drolet GG, Barr AA, Black TA (2009) Can a satellite-derived estimate of the fraction of PAR absorbed by chlorophyll (FAPAR(chl)) improve predictions of light-use efficiency and ecosystem photosynthesis for a boreal aspen forest? Remote Sens Environ 113:880-888. https://doi.org/10.1016/j.rse.2009.01.002

Zhang QY, Middleton EM, Cheng YB, Landis DR (2013) Variations of foliage chlorophyll fAPAR and foliage non-chlorophyll fAPAR (fAPARchl, fAPARnon-chl) at the Harvard Forest. IEEE J Sel Top Appl Earth Obs Remote Sens 6:2254-2264. https://doi.org/10.1109/jstars.2013.2275176 
Zhang Q et al (2016) Integrating chlorophyll fAPAR and nadir photochemical reflectance index from EO-1/ Hyperion to predict cornfield daily gross primary production. Remote Sens Environ 186:311-321. https://doi.org/10.1016/j.rse.2016.08.026

Zhao M, Running SW (2010) Drought-induced reduction in global terrestrial net primary production from 2000 through 2009. Science 329:940-943. https://doi.org/10.1126/science.1192666

Publisher's Note Springer Nature remains neutral with regard to jurisdictional claims in published maps and institutional affiliations. 